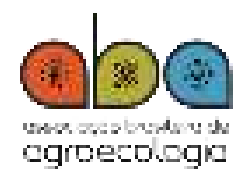

ISSN: $1980-9735$

DOI: $10.33240 /$ rba.v14i2.22946

Vol. 14 | No. 2 Esp.| p. $22-34$ | 2019

\title{
A TRANSIÇÃO PARA UM SISTEMA AGROALIMENTAR MAIS SUSTENTÁVEL: O PAPEL DA AGROECOLOGIA E SUAS MUDANCAS EPISTEMOLÓGICAS
}

Transition to a more sustainable agri-food system: the role of agroecology and its epistemological changes

Pauline Hélène Cécile Marie Cuenin'; Maria Izabel Vieira Botelho²; Daniel Silva do Carmo Santos ${ }^{3}$; Marcelo Leles Romarco de Oliveira ${ }^{4}$ e Irene Maria Cardoso ${ }^{5}$
${ }^{1}$ Mestre em Extensão Rural,

Departamento de Economia Rural,

Universidade Federal de Viçosa (UFV);

E-mail: pauline.cuenin3@gmail.com;

${ }^{2}$ Professora Doutora do Programa de

Pós-Graduação em Extensão Rural; Email: mbotelho@ufv.br;

${ }^{3}$ Mestre em Extensão Rural,

Departamento de Economia Rural,

Universidade Federal de Viçosa (UFV);

E-mail: danielsantos_d@hotmail.com;

${ }_{4}$ Professor Doutor do Programa de Pós

Graduação em Extensão Rural; E-mail:

marceloromarco@gmail.com;

5 Professora Doutora do Departamento

de Solos, Universidade Federal de

Viçosa (UFV); E-mail: irene@ufv.br

\section{Recebido em:}

08/04/2019

Aceito para publicação em:

15/05/2019

Correspondência para:

pauline.cuenin3@gmail.com

\section{RESUMO}

Diante dos múltiplos problemas ambientais, sociais e econômicos do atual sistema agroalimentar global, os desafios são vários. Dentre eles, destaca-se a necessidade de elaboração de novas epistemologias. A Agroecologia traz novas bases epistemológicas com vistas à construção de um sistema agroalimentar mais sustentável e justo. Este artigo objetiva apontar as principais mudanças epistemológicas presentes na proposta agroecológica e suas potenciais implicações práticas em direção a um sistema agroalimentar mais sustentável. Assim, por meio da análise, primeiramente, dos fundamentos da construção dos conhecimentos da ciência moderna e depois, dos fundamentos da Agroecologia, constatou-se um pluralismo epistemológico na Agroecologia, que se alicerça na visão holística dos sistemas, integrando a coevolução dos processos sociais e naturais, o diálogo da diversidade dos saberes e na admissão das questões éticas e ideológicas. O estabelecimento dessas novas bases epistemológicas, associadas a novos focos metodológicos, permite mudanças nas práticas agrícolas, nos valores e comportamentos dos cidadãos, promovendo uma filosofia da ética.

Palavras-chave: Ciência. Epistemologias. Transição Agroecológica. Diálogo de Saberes.

\section{ABSTRACT}

Given the multiple environmental, social and economic problems of the current global agri-food system, the challenges are many and diverse. Among them, can be highlighted the need to elaborate new epistemologies. Agroecology brings new epistemological bases for the construction of a more sustainable and fair agri-food system. This article aims to point out the main epistemological changes present in the agroecological proposal and its potential practical implications towards the more sustainable agri-food system. Thus, through the analysis, firstly, of the foundations of the construction of the knowledge of modern science and later, of the foundations of Agroecology, an epistemological pluralism was verified in Agroecology, which is based on the holistic vision of the systems, integrating the coevolution of the social and natural processes, a dialogue between the diversity of knowledges and the admission of ethical and ideological questions. The establishment of these new epistemological bases associated with new methodological focuses allows changes in agricultural practices, values and behaviors of citizens, promoting a philosophy of ethics.

Keywords: Science. Epistemologies. Agroecological Transition. Dialogue of Knowledges. 
Introdução

A atual crise da modernidade permeia diferentes esferas da vida humana, em diferentes sociedades. No que se refere ao sistema agroalimentar mundial, os problemas conhecidos de degradação ambiental, de conflitos sociais, de insegurança alimentar e nutricional são elementos visíveis de uma crise mais profunda global, multifacetada e persistente (ALTIERI e TOLEDO, 2010; GLIESSMAN, 2002; NZAMUJO, 2015; ROBERTS, 2008). Essa crise provém de processos complexos dos quais se destaca a aplicação do capitalismo industrial à agricultura, o que introduziu a economia de escala e a eficiência mecânica na natureza. Com isso, a lógica "racional", no sentido moderno, e industrial superou a lógica natural. Os ciclos naturais e os processos ecológicos foram rompidos, gerando uma desconexão da agricultura com a natureza (POLLAN, 2006; ROBERTS, 2008; VAN DER PLOEG, 2009) e o surgimento e a ampliação dos principais problemas ambientais. Além disso, a liberalização dos mercados ao nível global e a concentração dos mercados alimentares, por algumas empresas, exercem forte pressão sobre os(as) agricultores(as) e os(as) consumidores(as), o que tem promovido conflitos sociais decorrentes da dificuldade de produzir e competir. Ademais, o incremento da economia de escala não superou os problemas de insegurança alimentar; ao contrário, estes vêm adquirindo grandes dimensões em todo o mundo (VAN DER PLOEG, 2009).

Nesse cenário de crise, cujos interesses econômicos dominam o funcionamento do sistema agroalimentar global, a ciência moderna e seus modelos de pensamento tiveram, e ainda têm, um papel não negligenciável (ESCOBAR, 2014; IAASTD, 2009), em particular, por meio da implementação do modelo de produção agrícola preconizado pela Revolução Verde (metade do século XX), assim como no incentivo ao estabelecimento e à ampliação do agronegócio atualmente. De fato, esses modelos se baseiam em paradigmas científicos guiados por uma racionalidade formal ou instrumental, que se quer neutra, absoluta, universalizante e portadora da verdade (SANTOS, 1988, 1989). Seguindo os princípios capitalistas de transformação e de dominação da natureza, bem como de acumulação de capital, a ciência moderna produz conhecimentos para a criação de inovações tecnológicas com a intensificação do ritmo da produção capitalista e da capacidade de produção (FERREIRA, 2016). Essas tecnologias, condicionadas pelos interesses do mercado, tornam os(as) agricultores(as) cada vez mais dependentes e sujeitos a elas e aos fornecedores desses aparatos técnicos, reduzindo fortemente sua autonomia.

Diante dessa crise da modernidade, sem futuro sustentável, o desafio é epistemológico. Diferentes estudiosos, europeus e latino-americanos (MORIN, 2011; SANTOS, 1989) apontam para a necessidade de caminhar para uma transição epistemológica, com vistas a repensar a ciência e, portanto, reinventar o presente em direção a um futuro sustentável, justo e equitativo. Essas mudanças de visões de mundo e de paradigmas têm repercussões nas regras e práticas em diferentes níveis, bem como as mudanças nas práticas podem contribuir para o estabelecimento de um novo paradigma. De fato, qualquer transição é um processo gradual e contínuo de um conjunto de mudanças conectadas. Assim, cada mudança reforça outra mudança, em uma espiral que se reforça por si mesma, em uma forma de coevolução, envolvendo tecnologias, instituições, cultura, sistemas de crença, etc. (MOORS et al., 2004).

No processo de transição agroecológica, deve-se procurar integrar e articular pesquisa, educação e ações que promovam mudanças nas dimensões ecológica, econômica e social do sistema agroalimentar, tornando-o mais sustentável e justo (GLIESSMAN, 2018). Para isso, a Agroecologia necessita de mudanças epistemológicas, algumas delas apresentadas neste artigo, bem como suas potenciais implicações práticas em direção a um sistema agroalimentar mais sustentável.

\section{Modelo produtivista na agricultura e suas implicações: a crise epistemológica da ciência moderna}

\section{A ciência moderna e suas críticas}

A modernidade ocidental, definida de maneira ampla como modos de vida e ideias que rompem com o antigo, transformou diferentes setores da sociedade com extrema rapidez, com influência mundial, desde o colonialismo, impondo-se como o único mundo possível, porque "civilizado, livre e 
racional" (ESCOBAR, 2014). Nesse processo, a civilização e a história ocidentais, incluindo a ciência moderna como parte do projeto civilizador da Europa (FERREIRA, 2016), tornaram-se narrativa hegemônica com a expansão de conhecimentos ditos "universais", desqualificando e negando os modos de vida, as formas de pensamentos e de conhecimentos dos outros povos e comunidades. Sendo geograficamente situados e construídos a partir de histórias locais e regionais, esses saberes e modos de vida eram considerados como "irracionais" (MIGNOLO, 2013; PORTO-GONÇALVES, 2002; SANTOS, 1988). De fato, a origem da modernidade eurocentrada provém do Renascimento dos séculos XV e XVI com a teologia cristã que construiu um conhecimento fundamentado na supressão da sensibilidade e do seu enraizamento geo-histórico (MIGNOLO, 2000, 2013).

Em particular, a formação das bases conceituais, metodológicas e institucionais da ciência moderna se constituíram entre o século XVI e XVIII, até seu advento no século XVIII, período do Iluminismo, durante o qual se construiu um modelo de produção de conhecimentos, marcado pela separação entre a ciência e a teologia/filosofia, entre a razão e a moral (FERREIRA, 2016). Esse distanciamento da ciência com as questões teológicas e éticas foi o ponto central da revolução científica moderna, que traz consigo novas representações da natureza (FERREIRA, 2016). Essa maneira de pensar se expandiu no mundo ulteriormente por meio da filosofia das ciências, em particular, com o empirismo de Bacon (1561-1626) - visão pragmática da ciência e domínio do homem sobre a natureza - o racionalismo de Descartes (1596-1650) - a dominação da razão sobre os sentidos e a experiência - e, depois, com o positivismo de Comte (1798-1857) - geração do conhecimento a partir dos fatos (GOMES, 2005).

Essas três abordagens, mesmo sendo diferentes, visam a busca de um conhecimento válido, de verdade absoluta, em que a natureza é tida como objeto de estudo passivo e neutro, segundo os princípios mecanicistas (SANTOS, 1988). Conhecer a verdade é um princípio chave da ciência moderna, que está diretamente associado à busca da transformação da realidade e da dominação da natureza. 0 método matemático experimental se tornou a base para chegar a um conhecimento mais rigoroso e profundo da natureza para a produção de leis (SANTOS, 1988).

Hume (1711-1776) enfatizou as duas vias para chegar à "verdade" por meio do raciocínio experimental, que é o método científico o qual estabelece relações de causas-efeitos, e do raciocínio abstrato, ou seja, as demonstrações matemáticas (GOMES, 2005). Portanto, a ciência moderna e a produção de conhecimentos legítimos se baseiam no pensamento racional formal ou instrumental, com a supervalorização da quantidade em detrimento da qualidade, isso por meio da medida e do cálculo, ou seja, sem intervenção divina (GOMES, 2005; PORTO-GONÇALVES, 2002; SANTOS, 1988).

Para Santos (1989), a metodologia racionalista usada pela ciência moderna tem como consequência a primeira ruptura epistemológica, que consiste na separação da ciência e seu conhecimento "racional e válido" do senso comum e suas opiniões, o conhecimento vulgar e a experiência imediata. Nessa perspectiva, o senso comum é desvalorizado, visto como conhecimento "superficial e ilusório" (SANTOS, 1989).

A ciência moderna, ao querer entender a natureza para dominá-la (FERREIRA, 2016; GOMES, 2005; PORTO-GONÇALVES, 2002), criou um distanciamento do objeto de estudo do seu ambiente, transferindo-o em um ambiente artificial por meio dos métodos experimentais científicos (MORIN, 2000, 2011) e, portanto, contribuiu para a criação de várias dicotomias: natureza/cultura, mente/matéria, sujeito/objeto, animal/pessoa, prática/teoria, contemplação/ação (ESCOBAR, 2014; PORTO-GONÇALVES, 2002; SANTOS, 1988). Escobar (2014) afirma que a ontologia da modernidade é dualista, baseada nas separações citadas anteriormente.

O princípio da separação, que promoveu o afastamento do ser humano em relação ao seu lugar, ignorando a percepção imediata do espaço vivido (PORTO-GONÇALVES, 2002), deu resultado a um "conhecimento mutilado" (MORIN, 2000), "desencantado e triste" (SANTOS, 1989). Esse conhecimento mutilado e especializado se constitui em uma tradução simplificadora da realidade complexa (SANTOS, 1989). Com isto, os saberes se tornaram cada vez mais especializados e fragmentados em disciplinas (FERREIRA, 2016; SANTOS, 1989). Ao especializar-se cada vez mais, a ciência cai, geralmente, em modelos reducionistas que dissimulam a sua ideologia (ALVES, 1981; MORIN, 2011). 
No entanto, a ciência não é neutra porque a pesquisa se insere em um contexto maior que tem grande influência na construção do conhecimento, da escolha do tipo de pesquisa às teorias e métodos utilizados. Assim, por trás de cada pesquisa, se expressa certa ideologia (ALVES, 1981). Por meio da análise histórica, Ferreira (2016) mostrou o papel da ciência e das inovações tecnológicas na propulsão da produção industrial, no aumento da capacidade produtiva e do ritmo de produção capitalista. Assim, pode-se afirmar que existe uma disputa em torno da "verdade", que está, de certa forma, dependente dos interesses econômicos, já que o poder econômico exerce forte influência na produção do conhecimento.

Assim, a verdade da ciência moderna e a hegemonia do conhecimento ocidental, é questionável, já que a mesma estabeleceu fundamentos dogmáticos e deterministas que atuam de acordo com os interesses de um sistema de dominação de mundo, da base alimentar até a geração de tecnologia. É nessa ciência, que as ciências agrárias, dos alimentos e, de maneira mais geral, o sistema agroalimentar atual, se ancoram.

As ciências agrárias e ciências dos alimentos: da modernização da agricultura à globalização do sistema agroalimentar

A partir da segunda metade do século $X X$, os sistemas de produção de alimentos vigentes passaram a se orientar pelos princípios da modernização agrícola, com vistas à maximização da produção e do lucro, em curto prazo, com o uso, principalmente, da lavoura intensiva, monocultivo, uso de fertilizantes sintéticos, irrigação, controles químicos de pragas e ervas daninhas, além de manipulação genética (GLIESSMAN, 2002). Essa agricultura está associada ao desenvolvimento de pacotes tecnológicos "universais" realizados a partir da formulação de "receitas" em centros de pesquisa que poderiam ser empregadas em qualquer lugar pelo(a) agricultor(a) (ANDRADES, 2007). Os(as) agricultores(as) que entraram nesse modelo se tornaram extremamente dependentes dos insumos externos, ou seja, de tecnologias desenvolvidas pela ciência moderna, produzidas externamente às propriedades agrícolas (GLIESSMAN, 2002).

Os conhecimentos tradicionais e locais, baseados na experiência, na prática e em longos processos de coevolução entre o sistema social e biológico, são substituídos por tecnologias orientadas pela ciência moderna. A adoção de tais tecnologias transforma o sistema agrícola tradicional em sistema altamente tecnificado e especializado, o que se traduz em um distanciamento com as práticas locais e uma perda significativa sobre o controle do processo de trabalho dos(as) agricultores(as), dos povos e comunidades tradicionais (VAN DER PLOEG, 2009).

Nesse processo de modernização da agricultura, Van der Ploeg (1992) destaca múltiplas desconexões dos elementos estruturantes que faziam da agricultura uma especificidade (localidade e diversidade). Pode-se enfatizar a desconexão da agricultura com a natureza e, de maneira mais ampla, da natureza com a sociedade, no alongamento da cadeia alimentar do produto agrícola até o produto final, geralmente desnaturalizado (POLLAN, 2006). Em suma, percebe-se que a ciência e o desenvolvimento tecnológico, associados aos interesses do capital, são responsáveis por essas desconexões, remodelando a agricultura (VAN DER PLOEG, 1992) e fazendo desaparecer as localidades no sistema agroalimentar.

Atualmente, a estruturação das empresas multinacionais agrícolas e alimentares em segmentos que concentram a maioria dos mercados globais agrícolas e alimentares, como um novo modo de ordenamento controlando a produção, o processamento e a distribuição dos alimentos, constituídos nos chamados "Impérios Alimentares" (VAN DER PLOEG, 2008), visam o controle completo do sistema agroalimentar. Para isso, eles utilizam o chamado conhecimento científico moderno (VAN DER PLOEG, 2008), a exemplo, do controle das sementes geneticamente modificadas (popularmente denominadas sementes transgênicas) em laboratórios. De fato, diante dos limites das tecnologias agrícolas existentes, os "Impérios Alimentares" justificam a nova geração de tecnologias como solução milagrosa à crise agrícola moderna, necessárias para salvar o meio ambiente e acabar com a fome e a pobreza, a exemplo das sementes transgênicas (ROBERTS, 2008). 
Assim, os "Impérios Alimentares" usam a epistemologia da ciência moderna com as abordagens positivistas e reducionistas, assim como as argumentações mecanicistas para apresentar as tecnologias criadas como neutras e legitimar o sistema dominante (PETERSEN, 2015). De fato, nas ciências agrárias, a produção de conhecimento tinha, e ainda tem, um enfoque cartesiano e reducionista, e é baseada no método indutivo das relações causa-efeito e na experimentação repetitiva, cujos resultados são submetidos a testes estatísticos para constituir, então, uma verdade inquestionável (GOMES, 2005). Além disso, a avaliação e o controle dos resultados da ciência permanecem na esfera científica, desconsiderando as questões éticas (PETERSEN, 2015).

Entretanto, diante das crises agrícolas, alimentares e energéticas persistentes, a dominação desse conhecimento científico dentro do sistema agroalimentar global atual passou a ser questionado. Estes questionamentos têm apontado a necessidade de reforma do pensamento e do conhecimento, para o que é necessário repensar as bases epistemológicas da ciência (MORIN, 2000).

Na transição para novas bases epistemológicas, a Agroecologia procura romper com o paradigma convencional, reducionista e cartesiano (CAPORAL, 2009) para não reproduzir os mesmos esquemas negativos da ciência convencional e, assim, caminhar para um sistema agroalimentar mais sustentável. De fato, a Agroecologia traz novidades epistemológicas, em particular, as oriundas das experiências na América Latina (ALTIERI e TOLEDO, 2010), que podem ser as bases para a construção de um novo paradigma de ciência (GOMES, 2005).

\section{A agroecologia e as novas bases epistemológicas para um sistema agroalimentar mais sustentável}

\section{A integração dos saberes tradicionais locais e científicos para a construção de novos saberes e práticas}

Um dos princípios fundamentais da Agroecologia é o reconhecimento da importância dos conhecimentos locais e empíricos dos(as) agricultores(as), dos povos e das comunidades tradicionais e da necessidade destes conhecimentos para a promoção de um sistema agroalimentar sustentável (ALTIERI e TOLEDO, 2010; GLIESSMAN, 2018; TOLEDO, 2016). Na América Latina e, particularmente no Brasil, os(as) camponeses(as) foram essenciais na construção do movimento e da ciência agroecológica, pois a Agroecologia emergiu, nos anos finais da década de 1970, a partir das práticas agrícolas tradicionais locais (WEZEL et al., 2009). Com isso, a Agroecologia reconhece o que a ciência moderna desconsiderou, ou seja, o conhecimento empírico local dos(as) agricultores(as).

O papel do local é central na Agroecologia, por ser rico em bens, conhecimentos, sabedorias e tradições que potencializam a diversidade sociocultural. Isso se dá em contraposição à modernidade ocidental hegemônica, que é pensada como universal. De fato, para Santos (2002), esse modelo de racionalidade ocidental se baseia na monocultura do saber, os conhecimentos da ciência moderna como as únicas verdades; na monocultura do tempo linear, nos sistemas tradicionais como sistemas atrasados; na classificação social, colocando a posição de inferioridade como natural; na lógica da escala dominante, tornando as experiências locais insignificantes; na lógica produtivista capitalista, sendo o crescimento econômico o único caminho para seguir (SANTOS, 2002).

Por meio desse processo, produz-se a não existência de uma série de experiências consideradas inferiores, atrasadas, locais ou improdutivas. Santos (2002) propõe dar visibilidade às ausências pela "razão cosmopolita" com o questionamento da lógica de ocultação das diferentes realidades. Com isso, ele traz o conceito de ecologia (dos saberes, das temporalidades, etc.) para ajudar a revelar a diversidade e a multiplicidade das práticas com a valorização de outros saberes, outras temporalidades, do local e pelo reconhecimento recíproco das diferenças (SANTOS, 2002).

Assim, ao considerar os conhecimentos empíricos locais como centrais, a Agroecologia questiona e modifica os paradigmas que fundamentam a atual agricultura e, de maneira mais geral, o sistema agroindustrial de produção de alimentos (GLIESSMAN, 2002; TOLEDO, 2016). Dando importância ao valor epistêmico desses saberes, trata-se de "epistemologia natural" (ITURRA, 1993). 
Esse processo de questionamento do pensamento hegemônico ocidental está inserido no processo mais amplo de descolonização do pensamento europeu, que procura desenvolver epistemologias do Sul. Na América Latina, a Agroecologia está influenciada por essas "epistemologias do Sul" (TOLEDO, 2016). Segundo Mignolo (2013), com o "pensamento da fronteira", os conhecimentos locais precisam ser reconhecidos como partes legítimas de um todo. Na busca de uma visão do mundo diferente da ocidental, Acosta (2012) apresenta o "Buen Vivir" (Sumak Kawsay, em Kichwa, língua dos povos do Equador e Colômbia) como proposta de "paradigma" para repensar o desenvolvimento e construir novas formas de vida da "periferia para a periferia". O "Buen Vivir" é uma visão de mundo baseada na diversidade e na harmonia com a natureza, bem como na promoção de um diálogo permanente e construtivo de saberes ancestrais com os avanços tecnológicos da ciência universal (ACOSTA, 2012).

Assim, na Agroecologia, além do reconhecimento dos saberes locais e tradicionais, os conhecimentos empíricos são integrados aos conhecimentos científicos e métodos modernos (já que a ciência moderna traz avanços tecnológicos que não podem ser desconsiderados mas que precisam ser mais refletidos na sua aplicação) para a construção de novos saberes que alimentam o processo de transição (ALTIERI e TOLEDO, 2010; CAPORAL, 2009; GLIESSMAN, 2002). Essa união dos conhecimentos tradicionais e modernos é outra base epistemológica da Agroecologia, que já foi enfatizado por Norgaard, em 1989, e que é essencial no processo de mudanças (PETERSEN, 2015). De fato, para sair da lógica da dominação do pensamento ocidental e não criar outro tipo de dominação, não existem soluções prontas, mas aspirações.

Como Santos (2002), Morin (2000) e Marcos Terena, liderança indígena cujo discurso foi transcrito no livro de Morin (2000), enfatizam a importância de todos os saberes, que sejam globais ou locais, e das suas interações, com o objetivo de uma reforma do pensamento. É preciso um diálogo entre os saberes e valores de cada civilização contra a crise da modernidade (MORIN, 2000) para o "bem-viver" da humanidade (ACOSTA, 2012). Referente às implicações práticas, pode-se citar Freire (1985, p. 39): "Numa concepção não mecanicista, o novo nasce do velho através da transformação criadora que se verifica entre a tecnologia avançada e as técnicas empíricas dos camponeses".

Para efetuar esse diálogo entre saberes, é preciso integrar o trabalho de tradução, permitindo coerência e articulação da diversidade (SANTOS, 2002). A criação de inteligibilidade, entre diferentes experiências do mundo possibilita a agregação de saberes para a construção de novos saberes. Para alcançar esse diálogo, a Agroecologia propõe novos focos metodológicos, buscando métodos de estudo e de intervenção que sejam participativos (CAPORAL, 2009). Assim, questiona-se o esquema convencional de transferência de conhecimentos que separa a pesquisa, o ensino e a extensão. De fato, as condições epistêmico-metodológicas devem ser claras para permitir a integração de saberes de forma não subordinada (CAMPOS, 1990). Gomes (2005) fala de "epistemologia da participação".

A produção de novos saberes e a expansão do conhecimento por vias horizontais são resultados da construção de espaços de aprendizagem, de reflexão coletiva e participante, que são realizados por meio de redes de diferentes atores, como agricultores(as), especialistas, etc. No relatório da Organização das Nações Unidas (ONU, 2010), a participação dos(as) agricultores(as) nesses espaços de aprendizagem e de sociabilidade é enfatizado como essencial para a construção do conhecimento agroecológico e a criação de soluções inovadoras.

A metodologia "Campesino a Campesino" é uma das metodologias conhecidas por sua grande contribuição em potencializar, socializar e difundir os conhecimentos e técnicas dos(as) agricultores(as). Essa metodologia pode ser considerada um sistema de métodos, procedimentos e técnicas que facilitam o desencadeamento de processo de intercâmbio e de aprendizagem entre os camponeses(as) e suas famílias, assim como entre dirigentes, técnicos(as), pesquisadores(as) e outros atores relacionados (SOSA et al., 2012). Assim, a Agroecologia indica metodologias para sistematizar e compartilhar diversos saberes a respeito do sistema agroalimentar, analisá-los e ampliá-los (FRANCIS et al., 2003).

No Brasil, na Zona da Mata de Minas Gerais, foram desenvolvidas metodologias de construção de conhecimentos e de trocas de saberes que contribuíram para o desenvolvimento de ambientes de inovação, tais como a experimentação participativa, as caravanas territoriais, as instalações artísticopedagógicas, etc. (SCHMITT, 2016). Em particular, elaborou-se a metodologia dos Intercâmbios 
Agroecológicos em 2007, fruto de uma trajetória de interações entre agricultores(as), movimento sindical, técnicos(as) do Centro de Tecnologias Alternativas da Zona da Mata, professores(as) e estudantes universitários na busca da construção dos conhecimentos agroecológicos por meio de métodos participativos e da educação popular (ZANELLI, 2015). Os Intercâmbios Agroecológicos são espaços nos quais as informações e os conhecimentos são renovados, aprofundados e mais facilmente apreendidos durante os momentos de socialização, nos quais se reconhece e se fortalece a capacidade de experimentar, de praticar e de viver a Agroecologia dos(as) agricultores(as) (ZANELLI et al., 2015).

Nessa perspectiva, as trocas de saberes, a partir destas novas metodologias, são importantes estratégias educativas, o que possibilita mudanças nas práticas de manejo dos agroecossistemas, nas relações entre agricultores(as), e entre agricultores(as), técnicos(as) e pesquisadores(as). Ao trazer novos conhecimentos, ao mesmo tempo em que se reconhece a capacidade de experimentação dos(as) agricultores(as), esses novos enfoques teóricos e metodológicos da Agroecologia permitem dar mais autonomia aos(às) agricultores(as). A Agroecologia favorece, ademais, outros tipos de pesquisa, participativa e descentralizada, com colaboração dos(as) agricultores(as), o que permite a emergência de novidades transformadoras das suas práticas e reforçadoras do novo marco referencial da Agroecologia.

Assim, ao reconhecer a importância dos(as) agricultores(as) ou camponês(a), do lugar e do conhecimento tradicional, e ao integrá-los com os conhecimentos e métodos científicos, por meio de novas bases epistemológicas e metodológicas, a Agroecologia incentiva os processos de criatividade de soluções locais, tecnológicas, sociais ou organizativas inovadoras mais sustentáveis, que melhoram o nível de vida da população.

A visão holística da Agroecologia, do enfoque interdisciplinar à reconexão com a natureza: repensar a complexidade

Um outro princípio fundador das bases epistemológicas da Agroecologia é sua visão integral ou holística com vistas a entender a complexidade e as relações em diferentes níveis e dimensões (FRANCIS et al., 2003). Nesse objetivo, a Agroecologia integra várias formas de saberes como já destacamos na parte anterior, mas também, várias dimensões (ecológica, agronômica, socioeconômica, sociopolítica, cultural, territorial, institucional, etc.) e, então, vários campos de conhecimentos, fazendo uma abordagem multi (uso de várias disciplinas justapostas para tratar uma questão), inter (ligação e coordenação entre diferentes disciplinas para tratar uma questão) e transdisciplinar (entrecruzamento de conceitos e métodos usados em diferentes disciplinas para tratar uma questão) (CAPORAL, 2009; GLIESSMAN, 2018; HECHT, 1993), em que combina ciências naturais com ciências sociais.

Nesta combinação, a Agroecologia contribui para reequilibrar a coevolução social e ecológica, unindo disciplinas híbridas (ecologia política, etnoecologia, etc.) e para ter uma visão mais ampla dos agroecossistemas e do sistema agroalimentar como sistemas socioecológicos (ALTIERI e TOLEDO, 2010; CAPORAL, 2009; NORGAARD, 1989 ; FRANCIS et al., 2003). Essa abordagem interdisciplinar vai na contramão da especialização científica, do desenvolvimento dos modelos reducionistas e do conhecimento parcelado (FRANCIS et al., 2003), bem como permite repensar e redescobrir a complexidade da realidade. De fato, como Morin (2000) enfatiza, é preciso pensar complexo diante dessa crise da modernidade e reconhecer o problema da complexidade e as incertezas, em vez de afirmar verdades inquestionáveis. Entretanto, para isso, deve-se reaprender, ou seja, reformar as estruturas do pensamento relacionando "partes ao todo, e o todo a nós" (MORIN, 2000, p. 33), o que a Agroecologia propõe em uma visão holística e sistêmica.

Nessa visão holística, a integração dos processos naturais e sociais, em sistemas socioecológicos, se destaca como base epistemológica da Agroecologia (ALTIERI e TOLEDO, 2010; FRANCIS et al., 2003; NORGAARD, 1989). Com base nas premissas epistemológicas para a Agroecologia de Norgaard (1989), Gomes (2005) associou esse enfoque coevolutivo dos sistemas naturais e sociais com a "epistemologia evolucionista". Essa coevolução estabelecida entre as dimensões social e biológica destaca a importância da coprodução (a interação e transformação mútua entre o ser humano e natureza viva), que corresponde ao modo camponês de fazer agricultura (ALMEIDA, 2009; VAN DER PLOEG, 2008). De 
fato, não se pode esquecer que os marcos teóricos e metodológicos da Agroecologia se fundamentam nos marcos sociais do campesinato (SEVILLA GUZMAN e MOLINA, 1996).

Pensar as relações de coevolução do ser humano com a natureza e, de maneira mais ampla, pensar complexo, é admitir o ser humano como parte da natureza (FRANCIS et al., 2003; MORIN, 2000). O enfoque holístico da Agroecologia vem, por um lado, da influência das Epistemologias do Sul, da cosmovisão dos povos e comunidades tradicionais (ALTIERI e TOLEDO, 2010) e, por outro, do pensamento e princípios ecológicos (GLIESSMAN, 2015), que buscam reconectar os diferentes elementos estruturantes do agroecossistema e do sistema agroalimentar e, em particular, os seres humanos com a natureza, que a ciência moderna e a lógica do capital quebraram.

Essa articulação do ser humano com a natureza corresponde a uma nova forma de pensar, uma outra racionalidade, que vai além da exploração da natureza e da lógica do capital. O(a) agricultor(a) se torna mais atento à lógica da natureza, aos processos naturais e ao seu ambiente circundante. A natureza deixa de ser um objeto sem vida. Pensar que os objetos da natureza estão sem vida corresponde a uma visão reducionista do mundo (INGOLD, 2011).

Em muitas sociedades não ocidentais, considerar os modelos locais da natureza significa considerar uma continuidade entre o mundo biofísico, humano e supranatural (ESCOBAR, 2005, 2014). Nos estudos das sabedorias tradicionais (etnoecologia), Toledo e Barrera-Bassols (2009) relevam as interrelações complexas entre o "corpus" de conhecimentos, as crenças ("kosmos") e as práticas ("praxis"). Para os povos e comunidades tradicionais, existem modelos de representações específicas da natureza e da terra, vistas como "fontes primárias da vida que nutrem, mantêm e ensinam" (TOLEDO, 2001, p. 8). A partir dessas representações e interpretações, os(as) agricultores(as) tomam decisões sobre as práticas de manejo dos agroecosistemas (BARRERA-BASSOLS e TOLEDO, 2005; TOLEDO, 2001).

Na América Latina, a Agroecologia se desenvolveu em consonância com as "epistemologias do Sul", como visto no tópico anterior, pois ela se fundamenta nessa cosmovisão holística dos povos e comunidades tradicionais, centrada na harmonia com a natureza (ACOSTA, 2012). Trata-se de uma visão biocêntrica e não antropocêntrica, na qual todos os seres vivos têm um mesmo valor ontológico (ACOSTA, 2012). Escobar (2014) fala de ontologias relacionais para enfatizar a continuidade de vínculos entre todas as entidades do mundo: os seres (humanos, não humanos incluindo os seres sobrenaturais) não existem por si mesmos, mas através da infinidade de relações. Assim, a reconexão do ser humano com a natureza permite ir além das dicotomias assimétricas teoria-prática, natureza-cultura, conhecerfazer, sujeito-objeto, a partir das quais se constituiu a modernidade ocidental, que justificou sua lógica depredadora (ACOSTA, 2012; ESCOBAR, 2014).

A dimensão supranatural, a espiritualidade, mesmo na Agroecologia, foi, em geral, marginalizada por questões políticas ou técnicas, mas é muito importante nas mudanças para práticas agroecológicas, respeitosas da natureza (BOTELHO et al., 2016). O ser humano, a natureza e o "kosmos" são vistos como um todo pelos indígenas. Terena, citado em Morin (2000), fala da "magia da vida", do "espírito da floresta", contrapondo à ciência moderna que separou o pensamento racional e técnico do pensamento simbólico e mitológico na ilusão de eliminar a subjetividade.

A visão holística do mundo, que integra as interligações das diferentes partes, permite refletir sobre a complexidade do pensar e fazer ciência. Nesse sentido, se pode perceber que os(as) agricultores(as) inseridos(as) na Agroecologia têm uma visão mais ampla das interações dos elementos dos agroecossistemas, das "bondades" ou benefícios da natureza, vistos como presentes divinos (BOTELHO et al., 2016). Portanto, caminhar para uma visão do mundo holística e relacional é essencial para nutrir e estimular a invenção de práticas respeitosas do meio ambiente, bem como dos outros seres humanos, e garantir a sobrevivência no local (ESCOBAR, 2014).

Nas ciências, os conceitos e princípios da Ecologia estabelecem, também, uma compreensão inclusiva, totalizante e holística da vida e do meio. No campo agroecológico, isso se traduz na análise dos problemas ou variáveis, considerando o problema como parte de uma unidade mais ampla, isto é, a partir de uma visão que leva em conta o contexto geral, ao invés de olhar para problemas singulares e limitados (GLIESSMAN, 2015; LEFF, 2010). De fato, o campo da Ecologia comporta teorias que consideram a realidade como relacional, os seres sendo interligados e interdependentes, portanto, 
parte de uma perspectiva sistêmica e complexa para pensar o ser humano como parte do ecossistema (FRANCIS et al., 2003).

Por exemplo, estudos na Zona da Mata de Minas Gerais com agricultores(as) que desenvolveram sistemas agroflorestais (BOTELHO et al., 2016) e agricultores(as) agroecológicos(as) (CUENIN, 2019) mostraram como as mudanças nas suas concepções de ver e de entender a natureza, trazidas e/ou incrementadas pela Agroecologia, permitiram reforçar as observações das diferentes partes do agroecosistema e suas relações. Portanto, na busca de um equilíbrio entre as partes, o desenvolvimento da visão holística e sistêmica pelos(as) agricultores(as) permitiu favorecer a experimentação de novas práticas, fundamentais na caminhada para uma transição para um sistema agroalimentar mais sustentável (CUENIN, 2019).

Assim, as mudanças na concepção da natureza para uma visão holística e sistêmica transformam o sujeito em um elemento que é parte do sistema, horizontalizando as relações entre os seres. Isso pode, inclusive, responsabilizar mais os(as) consumidores(as) no desenvolvimento de um sistema agroalimentar mais justo e, ao mesmo tempo, ampliar a consciência dos(as) agricultores(as) no que diz respeito à qualidade dos produtos (FRANCIS et al., 2003), ou, ainda, responsabilizar o(a) pesquisador(a) sobre as consequências das suas descobertas. Em outras palavras, pensa-se em uma reconexão entre a natureza e o ser humano e, de maneira geral, entre a natureza e a sociedade, permitindo aos seres humanos tomar consciência das ligações que estruturam o mundo. Nesse sentido, a Agroecologia se posiciona e considera os problemas éticos na construção e avaliação da ciência (FRANCIS et al., 2003; PETERSEN, 2015).

\section{Reaproximar a ética ecológica e social da prática científica para reposicionar a ciência na sociedade}

Com a intenção de promover um sistema agroalimentar mais justo, a Agroecologia busca construir essa nova relação entre a sociedade e a natureza, incluindo pesquisas que consideram os aspectos éticos (ALTIERI e TOLEDO, 2010). Petersen (2015), ao caracterizar as retóricas utilizadas pela ciência moderna para justificar e ocultar os males dos agrotóxicos, mostra como a razão moral e ética é separada da razão científica para ocultar os efeitos negativos dos agrotóxicos.

Apoiando-se em Funtowicz e Ravetz (2000), Petersen (2015) retoma a ideia de que toda a sociedade deveria participar da avaliação da ciência e da tecnologia para sair do autocontrole da ciência feito por pares da comunidade de especialistas e influenciada pelos interesses econômicos, assim como pelas relações de poder. Para além disso, Santos (1989), em seu livro sobre a ciência pós-moderna, propõe, através do diálogo e da superação da distinção entre as sabedorias do senso comum e da ciência, ou seja, da segunda ruptura epistemológica, uma democratização da ciência com uma transição para uma "epistemologia pragmática". De fato, o autor destaca uma estratégia de mudança para uma sabedoria que seria, desde então, reflexiva, prática, emancipadora e democrática pela ampla distribuição das competências cognitivas (SANTOS, 1989). Mais do que a distribuição, a construção democrática dos conhecimentos é fundamental para a transição para um mundo mais sustentável e justo (ACOSTA, 2012).

A Agroecologia procura promover essa democratização na produção de conhecimentos pela integração de todos os saberes e pela circulação de conhecimento, no qual as tomadas de decisão, a construção e a validação dos conhecimentos devem ser feitas para além das comunidades científicas e devem ser abertas a um debate mais amplo com toda a sociedade (GOMES, 2005). Para sair dos critérios de validez associados à dita "objetividade" da ciência, é preciso ter uma "aceitação dialógica e dialética do outro e da diferença" (GOMES, 2005, p. 8). Santos (1989, p. 181) trata de um outro modelo de aplicação do conhecimento no qual: "...quem aplica seja existencial, ética e socialmente comprometido com o impacto da aplicação".

O cientista deve estar consciente e levar em consideração valores éticos e históricos em sua pesquisa. Para "contribuir" para esta tomada de consciência, os cientistas poderiam ser responsabilizados pelas consequências das suas pesquisas. 
Em outras palavras, essa ciência democratizada enfatiza uma nova cidadania pelo direito de conhecer e participar dos debates e decisões sobre as opções tecnológicas que afetam o conjunto da sociedade (PETERSEN, 2015). A luta pelo direito fundamental do cidadão de participar nas tomadas de decisões tecnológicas é, também, destacado por Morin (2000). A partir do conceito de bioética, o autor afirma que os problemas revelados devem ser colocados em cena pública, para provocar uma consciência pública e política, pois "somente uma consciência pública pode controlar a ciência" (MORIN, 2000, p. 44).

A ética ecológica e social, que a Agroecologia sugere, pode ser visibilizada também por uma nova articulação entre o(a) agricultor(a) e o(a) consumidor(a), o que corresponde à última etapa da transição agroecológica, quando a agricultura propicia maior relação entre a natureza e a sociedade, segundo Gliessman (2011). O objetivo da Agroecologia em envolver todas as partes se traduz também na inclusão do(a) consumidor(a) em seus processos educativos, para que o(a) mesmo(a) se conscientize, se eduque e passe a compreender as conexões do sistema agroalimentar (FRANCIS et al., 2003) com sua própria vida. Essa compreensão permite ao(à) consumidor(a) ter opinião e poder avaliar esse sistema e se responsabilizar nas suas escolhas, como um "ato ecológico, agrícola e político" (POLLAN, 2006, p. 18).

A aproximação entre agricultores(as) e consumidores(as) contribui, também, para reforçar a responsabilidade dos(as) agricultores(as) na produção de alimentos saudáveis para os(as) consumidores(as) (FRANCIS et al., 2003). Esse processo contrabalança o funcionamento do sistema agroalimentar controlado pelos "Impérios Alimentares", no qual os(as) agricultores(as) estão "livres de preocupações e de responsabilidade" com relação à qualidade dos produtos, devido ao rompimento do elo agricultores(as)-consumidores(as), sendo a quantidade a principal preocupação (POLLAN, 2006).

São várias as experiências agroecológicas que favorecem a aproximação e o envolvimento dos(as) agricultores(as) e consumidores(as) com vistas a sistema agroalimentar mais sustentável, como as feiras livres agroecológicas ou a implementação de Comunidades que Sustentam a Agricultura (CSA). Em uma CSA, há compromissos, envolvimento e corresponsabilidade entre agricultores(as) e consumidores(as) com os processos e imprevistos de produção, compartilhando os riscos e os benefícios (HITCHMAN, 2015; PENEIREIRO; SILVA, 2017). Esse novo modelo alternativo de agricultura e distribuição de alimentos rompe com a lógica do mercado, trazendo a economia solidária e novas bases que procuram o bem viver (PENEIREIRO; SILVA, 2017).

Considerações finais

As abordagens reducionistas e cartesianas da ciência moderna ocidental fundamentaram as ciências agrárias que, desde a metade do século $X X$, têm sido orientadas pelo modelo produtivista proposto pela chamada Revolução Verde e que, atualmente, propagam o agronegócio com seu sistema agroalimentar insustentável. Essas perspectivas tendem a separar a ética da prática científica no objetivo de trazer conhecimentos que pretendem ser objetivos e neutros, ou seja, portadores de verdade inquestionável. As empresas multinacionais que controlam o sistema agroalimentar mundial usam dessas argumentações para justificar suas ações, desqualificar e ocultar as outras alternativas e outros tipos de conhecimentos.

Além disso, na concepção da ciência moderna, o saber é, geralmente, gerado com a separação do objeto de estudo do seu ambiente, ou seja, são produzidos conhecimentos muito especializados que desconsideram as interações do objeto com o seu lugar (biofísico e social). Esses modelos simplificadores não levam em consideração a complexidade do mundo, da natureza e suas múltiplas interações, portanto, permanecem a serviço das relações de poder e dos interesses econômicos que percebem a natureza como um simples objeto passivo a ser explorado.

Diante dessa ciência ocidental hegemônica, que traz insustentabilidade para o sistema agroalimentar em várias dimensões, há necessidade de mudanças epistemológicas da ciência para contribuir para o desenvolvimento de um sistema agroalimentar mais sustentável. Na busca por estas mudanças, a Agroecologia, em suas dimensões enquanto ciência, prática e movimento, contribui para a 
construção de um novo paradigma, orientada por bases epistemológicas inovadoras. Essas novas bases epistemológicas são fundamentais para a transição do sistema agroalimentar atual, pois implicam mudanças nas práticas. Entretanto, não se pode esquecer que o processo de transição é dinâmico, que as mudanças ao nível macro têm repercussões sobre os outros níveis e que as modificações nesses níveis também têm influência nas mudanças das bases epistemológicas.

Assim, pode-se constatar um pluralismo epistemológico na Agroecologia que se alicerça: na visão holística dos sistemas, integrando a coevolução dos processos sociais e naturais, em sistemas socioecológicos, e a combinação de várias dimensões e técnicas de pesquisa em uma perspectiva interdisciplinar; no diálogo da diversidade dos saberes envolvendo contextos e soluções variados na construção do conhecimento agroecológico; na admissão das questões éticas e ideológicas o que envolve a responsabilidade do(a) cidadão(ã) (cientista, consumidor(a), agricultor(a), técnico(a) etc.) na construção da ciência e do sistema agroalimentar. Essas bases epistemológicas, acompanhadas por bases metodológicas participativas, articulam a pesquisa, o ensino, a extensão, a partir de processos participativos e democráticos. O estabelecimento dessas novas bases epistemológicas e metodológicas permite, também, mudanças nas práticas agrícolas, nos valores e comportamentos dos(as) consumidores(as) e, de maneira geral, dos(as) cidadãos(ãs), promovendo uma filosofia da ética.

\section{Agradecimentos}

À Universidade Federal de Viçosa (UFV), ao programa de Pós-Graduação em Extensão Rural pela construção do conhecimento científico; Ao Conselho Nacional de Desenvolvimento Científico e Tecnológico (CNPq) pelo apoio financeiro

\section{Referências}

ACOSTA, A. O Buen Vivir : uma oportunidade de imaginar outro mundo. In: BARTELT, D. D. (Org.). Um campeão visto perto. Uma Análise do Modelo de Desenvolvimento Brasileiro. Rio de Janeiro: Heinrich-B, 2012. p. 94-105. ALMEIDA, S. G. Construção e desafios do campo agroecológico brasileiro. In: AS-PTA (Org.). Agricultura Familiar camponesa na construção do Futuro. [S.I: s.n.], 2009. p. 67-83.

ALTIERI, M. A.; TOLEDO, V. M. La revolución agroecológica de América Latina : Rescatar la naturaleza, asegurar la soberanía alimentaria y empoderar al campesino. El Otro Derecho, n. 42, p. 163-202, 2010.

ALVES, R. Filosofia da ciência: Introdução ao jogo e suas regras. [S.I.] Editora brasiliense, 1981.

ANDRADES, T. O. Revolução verde e apropriação capitalista. CES Revista, v. 21, p. 43-56, 2007.

BARRERA-BASSOLS, N.; TOLEDO, V. M. Ethnoecology of the Yucatec Maya: Symbolism, knowledge and management of natural resources. Journal of Latin American Geography, n. 4, p. 9-41, 2005.

BOTELHO, M. I. V.; et al. "I made a pact with God, with nature, and with myself": exploring deep agroecology. Agroecology and Sustainable Food Systems, v. 40, n. 2, p. 116-131, 2016.

CAMPOS, A. Investigación participativa: reflexiones acerca de sus fundamentos metodológicos y de sus aportes al desarrollo social. Cuadernos de agroindustria y economía rural, n. 24, p. 129-146, 1990.

CAPORAL, F. R. Agroecologia: uma nova ciência para apoiar a transição a agriculturas mais sustentáveis. Savanas: Desafios e estratégias para o equilíbro entre sociedade, agronegócio e recursos naturais, p. 30, 2009.

CUENIN, P. H. C. M. Os processos de produção de novidades agroecológicas: um olhar a partir dos/as agricultores/as familiares e das suas experimentações na Zona da Mata de Minas Gerais. 2019. 195f. Dissertação (Mestrado em Extensão Rural) - Universidade Federal de Viçosa, Viçosa, 2019.

ESCOBAR, A. O lugar da natureza e a natureza do lugar: globalização ou pós-desenvolvimento? A Colonialidade do Saber: Eurocentrismo e Ciências Sociais - Perspectivas Latino-americanas, p. 33-49, 2005.

ESCOBAR, A. Sentipensar con la tierra : nuevas lecturas sobre desarrollo, territorio y diferencia. Medellín: Universidad Autónoma Latinoamericana, 2014.

FERREIRA, R. de S. Capitalismo, ciência e natureza: do ideário iluminista do progresso à crise ambiental contemporânea. 2016. 130 f. Tese (Doutorado em Extensão Rural) - Universidade Federal de Viçosa, Viçosa, 2016. FREIRE, P. Extensão ou comunicação? 8. ed. Rio de Janeiro, 1985.

FRANCIS C., et al. Agroecology: The Ecology of Food Systems. Journal of Sustainable Agriculture, v. 22, n. 3, p. 99118, 2003.

FUNTOWICZ, S.; RAVETZ, J. La ciencia posnormal : ciencia con la gente. Barcelona: [s.n.], 2000.

GLIESSMAN, S. Agroecologia : processos ecológicos en Agricultura Sostenible. Turrialba: LITOCAT, 2002.

GLIESSMAN, S. Agroecology and Food System Change. Journal of Sustainable Agriculture, v. 35, n. 4, p. 347-349, 
2011.

GLIESSMAN, S. Agroecology and Sustainable Food Systems. Agroecology and Sustainable Food Systems, v. 42, n. 6, p. 599-600, 2018.

GLIESSMAN, S. R. Agroecology : The Ecology of Sustainable Food Systems. Third Edit ed. [S.I.]: Taylor \& Francis Group, 2015.

GOMES, J. C. C. Bases epistemológicas da Agroecologia. In: DE AQUINO, A. M.; DE ASSIS, R. L. (Ed.). Agroecologia: princípios e técnicas para uma Agricultura orgânica sustentável. Brasilia: EMBRAPA Informação Tecnológica, 2005. p. 71-100.

HECHT, S. B. A evolução do pensamento agroecológico. Agroecologia e Desenvolvimento, n. 1, p. 4-20, 1993.

HITCHMAN, J. Agricultura Sustentada pela Comunidade: um modelo que prospera na China. Agriculturas, v. 12 , n. 2, p. 33-38, 2015.

INTERNATIONAL ASSESSMENT OF AGRICULTURAL KNOWLEDGE, SCIENCE AND TECHNOLOGY FOR DEVELOPMENT IAASTD. Agriculture at a crossroads : synthesis report. [S.I.], 2009.

INGOLD, T. Estar vivo: ensaios sobre movimento, conhecimento e descrição. Petrópolis: Editora Vozes, 2011.

ITURRA, R. Letrados y campesinos : el método experimental en la antropología económica. In: GUZMAN, E. S.; MOLINA, M. G. de (Org.). . Ecologia, Campesinado e Historia. Madrid: La Piqueta ed., 1993. p. 131-152.

LEFF, E. Epistemologia ambiental. 5. ed. São Paulo, 2010.

MIGNOLO, W. Géopolitique de la sensibilité et du savoir. (Dé)colonialité, pensée frontalière et désobéissance épistémologique. Mouvements, v. 73, n. 1, p. 181, 2013.

MIGNOLO, W. La colonialidad : la cara oculta de la modernidad. Estudios: revista de investigaciones literarias, $v$. 11, n. 33, p. 39-50, 2000.

MOORS, E. H. M.; et al. The Dynamics of Innovation: A Multilevel Co-Evolutionary Perspective. In: WISKERKE, J. S. C.; PLOEG, J. (Eds.). Seeds of Transition. Essays on novelty production, niches and regimes in agriculture, 2004.

MORIN, E. La voie : pour l'avenir de I'humanité. [S.I.]: Fayard ed., 2011.

MORIN, E. Saberes Globais e Saberes Locais : o olhar transdiciplinar. Rio de Janeiro: [s.n.], 2000.

NORGAARD, R. B. A base epistemológica da agroecologia. In: ALTEIRI, M. A. (Org.). . Agroecol. as bases científicas da Agric. Altern. PTA : FASE ed. Rio de Janeiro: [s.n.], 1989. p. 42-48.

NZAMUJO, G. Songhai intensive and regenerative agriculture: an agroecological system deploying Agrica's environnemental capital. In: FAO (Org.). Agroecology for food secutiry and nutrition. Rome: [s.n.], 2015.

ORGANIZAÇÃO DAS NAÇÕES UNIDAS - ONU. Report submitted by the Special Rapporteur on the right to food, Olivier De Schutter. General Assembly, Human Rights Council, 2010.

PENEIREIRO, F. M., SILVA, M. H. F. Comunidade que Sustenta a Agricultura (CSA): do preço para o apreço aprendizagem coletiva na lógica do bem viver. In: CONGRESSO LATINO-AMERICANO DE AGROECOLOGIA, 6., 2017, Brasília. Cadernos de Agroecologia. [S.I: s.n.], 2018.

PETERSEN, P. Prefácio : Um novo grito contra o silêncio. In: ESCOLA POLITÉCNICA DE SAÚDE JOAQUIM VENÂNCIO (Org.). Dossiê ABRASCO. Rio de Janeiro/São Paulo: Expressão Popular, 2015. p. 27-36.

POLLAN, M. O dilema do onívoro. Tradução de Cláudio Figueiredo. Rio de Janeiro: Editora Intrínseca Ltda., 2006. PORTO-GONÇALVES, C. W. Da Geografia às Geo-grafias: Um Mundo Em Busca de Novas Territorialidades. La guerra infinita Hegemonía y terror mundial, p. 217-256, 2002.

ROBERTS, P. O fim dos alimentos. [S.I.] Editora Campus, 2008.

SANTOS, B. de S. Introdução a uma ciência pós-moderna. [S.I: s.n.], 1989.

SANTOS, B. de S. Para uma sociologia das ausências e uma sociologia das emergências. Revista Crítica de Ciências Sociais, v. 63, p. 237-280, 2002.

SANTOS, B. de S. Um discurso sobre as ciências na transição para uma ciência pós-moderna. Estudos Avançados, v. 2, n. 2, p. 46-71, 1988.

SCHMITT, C. J. (Org). Agroecologia, políticas públicas e transições sociotécnicas: ampliação de escala de redes territoriais voltadas à promoção de uma agricultura de base ecológica. Universidade Federal Rural do Rio de Janeiro, Rio de Janeiro, 2016.

SOSA, B. M.; et al. Revolução Agroecológica: o movimento Camponês a Camponês da Anap em Cuba. São Paulo, 2012.

SEVILLA GUZMAN, E.; MOLINA, M. G. de. Sobre la Agroecologia: Algunas reflexiones en torno a la agricultura familiar en España. In: GARCIA DE LEON, M. A. (Org.). El campo y la Ciudad. Madrid: MAPA ed., 1996.

TOLEDO, V. M. A agroecologia é uma revolução epistemológica. Agriculturas, v. 13, n. 1, p. 42-45, 2016.

TOLEDO, V. M. Indigenous people and biodiversity. In: LEVIN, S. et al. (Org.). Encyclopedia of Biodiversity. [S.I.]: Academic P ed., 2001.

TOLEDO, V. M.; BARRERA-BASSOLS, N. A etnoecologia: uma ciência pós-normal que estuda as sabedorias tradicionais. Desenvolvimento e Meio Ambiente, v. 20, p. 31-45, 2009.

VAN DER PLOEG, J. D. Camponeses e Impérios Alimentares. [S.I.] UFRGS, 2008.

VAN DER PLOEG, J. D. El processo de trabajo agrícola y la mercantilización. In: GUZMAN, E. S. (Org.). Ecologia, Campesinado e Historia. Madrid: Ediciones, 1992. p. 163-195. 
VAN DER PLOEG, J. D. Sete teses sobre a agricultura camponesa. Revistas Agriculturas: Experiências em Agroecologia, n. Especial, p. 17-32, 2009.

WEZEL, A. et al. Agroecology as a science, a movement and a practice. Sustainable Agriculture, v. 2, p. 27-43, 2009.

ZANELLI, F. V. Educação do campo e territorialização de saberes: contribuições dos intercâmbios Agroecológicos. 2015. 146f. Dissertação (Mestrado em Educação) - Universidade Federal de Viçosa, Viçosa, 2015.

ZANELLI, F. V., et al. Intercâmbios Agroecológicos: Processos Educativos impulsionando a agroecologia. In: CORRÊA DA SILVA, HUR BEN; CAVALCANTI, DENISE CIDADE; PEDROSO, A. F. (Ed.). Pesquisa e Extensão para a Agricultura Familiar: no ambito da política nacional de assistencia técnica e extensao rural. 1. ed. Brasilia-DF: Ministério do Desenvolvimento Agrário, 2015. p. 355-363. 